\title{
Ocular Microbial Flora and Diabetes in Patients Undergoing Cataract Surgery
}

\author{
Mohammadreza Soleimani ${ }^{1}$, Sadegh Arab Baniasad², Shokrollah Assar ${ }^{3}$, Yousof Taghavi Tabrizi ${ }^{4}$ \\ ${ }^{1}$ Department of Ophthalmology, Clinical Research Development Unit (CRDU), Moradi Hospital, Rafsanjan University of \\ Medical Sciences, Rafsanjan, Iran. ${ }^{2}$ Rafsanjan University of Medical Sciences, Rafsanjan, Iran. ${ }^{3}$ Department of \\ Microbiology, Immunology of Infectious Diseases Research Center, Rafsanjan University of Medical Sciences, \\ Rafsanjan, Iran. ${ }^{4}$ Department of Ophthalmology, Clinical Research Development Unit (CRDU), Moradi Hospital, \\ Rafsanjan University of Medical Sciences, Rafsanjan, Iran.
}

\section{ABSTRACT}

\section{BACKGROUND}

Diabetes, having an impact on the immune system, will cause changes in the microbial flora of different organs. The aim of this study was to compare the ocular microbial flora of diabetic and non-diabetic patients as candidates for cataract surgery.

\section{METHODS}

In this cross-sectional study, 380 diabetic and non-diabetic patients undergoing cataract surgery were selected by convenience sampling method. After informed consent, fasting blood sugar (FBS) and $\mathrm{HbA}_{1} \mathrm{c}$ were measured. Then, microbial culture of the conjunctiva was performed before surgery. Data were analyzed by independent T-test and fisher's exact test.

\section{RESULTS}

Frequency of Staphylococcus coagulase-positive in diabetic/non-diabetic patients was $0 / 6$. The difference was significant $(\mathrm{p}=0.030)$. In addition, the frequency of funguses in diabetic/non-diabetic patients was 17/1 $(\mathrm{p}<0.001)$. Klebsiella, Staphylococcus coagulase-negative and Staphylococcus epidermidis in diabetic patients were higher than non-diabetics $(\mathrm{p}>0.05)$.

\section{CONCLUSIONS}

The results of this study showed that, the rate of Klebsiella, Staphylococcus coagulase-negative, Staphylococcus epidermidis and Fungal species in conjunctival of diabetic patients was higher than non-diabetic. Therefore, ophthalmologists need to consider the immunology points in diabetic patients undergoing cataract surgery.

\section{Corresponding Author: Yousof Taghavi Tabrizi, Medical School, Khalij Fars Blvd., Rafsanjan, Kerman, Iran. E-mail: drtaghavi14@gmail.com}

DOI: $10.14260 /$ jemds/2020/147

Financial or Other Competing Interests: None.

How to Cite This Article:

Soleimani M, Baniasad SA, Assar S, et al. Ocular microbial flora and diabetes in patients undergoing cataract surgery. J. Evolution Med. Dent. Sci. 2020;9(09):678681, DOI: 10.14260/jemds/2020/147

Submission 30-05-2019,

Peer Review 07-11-2019,

Acceptance 13-11-2019,

Published 02-03-2020.

\section{KEY WORDS}

Bacterial Infection, Conjunctivitis, Diabetes, Cataract 


\section{BACKGROUND}

The major population of microorganisms that reside in the eyes of healthy people are bacterial normal flora. These microorganisms play a significant and specific role in preserving health and normal function of conjunctiva. These bacteria, when disturbed, can promptly re-establish themselves. These organisms generally aren't cause of eye infection, but they have potential to become pathogenic in the specific condition such as immune deficiency. ${ }^{1}$ It was accepted that gram-positive bacteria, particularly coagulasenegative Staphylococci, are the main inhabitants of healthy eye. They are the main reason of postoperative infections. ${ }^{2}$ The conjunctival flora may be changed in special conditions, in newborn, immune deficient patients, contact lens wearers, and patients using immunosuppressive medications. ${ }^{3}$ Diabetes mellitus is one of the diseases that affects the immune system and reduces the effective function against infections. Diabetes may cause metabolic disorders can facilitate infection.4,5 Diabetes has negative effects on the eyes, including delayed cornea damage, the formation of various types of glaucoma, cataracts and, retinopathy. It has been reported postoperative endophthalmitis was higher in diabetic patients in comparison with Non-diabetic patients. ${ }^{6}$ Fernández-Rubio et al. planed a Study to assess the microbial pattern of diabetic patients who candidate for cataract surgery. They were chosen 5922 patients and showed 274 people had renal dysfunction. Diabetic patients have higher levels of Staphylococcus aureus, Enterococci, Streptococci and Klebsiella than non-diabetics also their result showed prevalence of conjunctival bacteria was higher in older patients than younger. ${ }^{7}$ Kawata, demonstrated a correlation between the diabetes and conjunctival infection. Result of his study showed elder diabetic patients have a higher frequency of positive bacterial culture in the conjunctiva before cataract surgery. ${ }^{8}$ The main goal of this study was to evaluate the conjunctival bacterial and fungal flora of diabetic patients and compare it to the Non-diabetic patients, in patients before cataract surgery.

\section{METHODS}

The population of this cross-sectional study consists of all patients referred to our hospital candidate for cataract surgery over a 12-month period from September 2017 to September 2018. Based on Moreno et al. ${ }^{9}$ (Distribution of Staphylococcus aureus in diabetic patients was $14 \%$ and in Non-diabetics $4.2 \%$, therefore, p1=0.14, p2 $=0.042$, with consideration $\alpha=0.05, \beta=0.2$,

$\left.\left.\mathrm{n}=\frac{\left(\mathrm{Z}_{1}-\frac{\alpha}{2}+\mathrm{Z}_{1}-\beta\right)^{2} \mathrm{P}_{1}\left(1-\mathrm{P}_{1}\right)+\mathrm{P}_{2}\left(1-\mathrm{P}_{2}\right)}{\left(\mathrm{P}_{1}-\mathrm{P}_{2}\right)^{2}}\right)=175.62\right)$

For more certainty, 190 patients selected by a convenience sampling method. This study approved by the Ethics Committee of Rafsanjan University of medical sciences (IR.RUMS.REC.1395.93). Patients with anatomical and functional defects such as corneal and conjunctival disorders and conjunctival secretions, known immunosuppressive diseases and ophthalmic medicine therapy were excluded from the study. Informed consent was obtained from all individuals. Before cataract surgery, fasting blood sugar (FBS) and $\mathrm{HbA1c}$ was measured. Also, the conjunctival swabs obtained by moistened sterile cotton tipped applicators in aseptic condition and appropriate light source, from both eyes of all the patients separately and sent to the microbiology laboratory of medical college. In the laboratory, the swabs were inoculated in Tryptic Soy Broth (TSB) at $37^{\circ} \mathrm{C}$ for 6 hours to exclude infection and gram staining was done from the broth and also cultured in blood agar and Eosin methylene blue and thioglycollate broth. All media incubated at $37^{\circ} \mathrm{C}$ for 24 hours. After 48 hours, all the creatures were recognized by normal microbiological techniques i.e. colony morphology, Gram staining, pigment creation.

\section{Statistical Analysis}

The clinical and laboratory records of all patients were coded, and data analyzed by SPSS-20. The results were presented as mean \pm standard deviation (SD). Independent t-test and fisher's exact test were used for analysis of data and p-value $\leq$ 0.05 was considered statistically significant.

\section{Ethical Considerations}

All procedures performed in studies involving human participants were in accordance with the Ethics Committee of our University of medical sciences, Iran, and with the 1964 Helsinki declaration and its later amendments or comparable ethical standards.

\section{RESULTS}

In this study, microbial culture was taken from the conjunctival cul-de-sac of both eyes, but only we analyzed and reported the cultures results of the eye under cataract surgery. A total data from 380 people were analyzed in this study. The mean age of patients with positive and negative microbial culture $(\mathrm{p}=0.220)$ and diabetic and non-diabetic patients was not significantly different $(0.052)$. There was no significance relation between gender and the result of microbial culture $(p=0.257)$ but the relation between gender and diabetes was significant $(\mathrm{p}=0.022)$ (Table 1). The result of Fisher's Exact Test showed that the relation between diabetes and the outcome of microbial culture was significant (0.032) (Table 2). The frequency of microorganisms in diabetic/non-diabetics patients were as follows: Klebsiella $3 / 0 \quad(\mathrm{p}=0.123)$, Staphylococcus coagulase-negative 40/26 $(\mathrm{p}=0.059), \quad$ Staphylococcus epidermidis $9 / 6 \quad(\mathrm{p}=0.600)$, Enterobacter $0 / 3 \quad(\mathrm{p}=0.248)$, Staphylococcus coagulasepositive $0 / 6(\mathrm{p}=0.030)$ and Funguses $17 / 1(\mathrm{p}<0.001)$ (Table 3 ). The frequency of the fungal species obtained showed in Table 4.

\begin{tabular}{|c|c|c|c|c|c|c|}
\hline & \multicolumn{2}{|c|}{ Microbial Culture } & \multirow[b]{2}{*}{$\begin{array}{c}\text { p- } \\
\text { Value }\end{array}$} & \multicolumn{2}{|c|}{ Diabetes } & \multirow[b]{2}{*}{$\begin{array}{c}\text { p- } \\
\text { Value }\end{array}$} \\
\hline & $\begin{array}{c}\text { Positive } \\
(n=62)\end{array}$ & $\begin{array}{c}\text { Negative } \\
(n=268)\end{array}$ & & \begin{tabular}{|c|} 
Yes \\
$(n=190)$
\end{tabular} & \begin{tabular}{|c|}
$\begin{array}{c}\text { No } \\
(n=190)\end{array}$ \\
\end{tabular} & \\
\hline "Age (years) & $69.28 \pm 10.12$ & $67.45 \pm 12.60$ & +0.220 & $66.69 \pm 8.67$ & $69.13 \pm 14.65$ & +0.052 \\
\hline $\begin{array}{c}\text { "Gender } \\
\text { Male(n=161) } \\
\text { Female }(\mathrm{n}=219)\end{array}$ & $\begin{array}{l}42(37.8) \\
69(62.2)\end{array}$ & $\begin{array}{l}119(44.2) \\
150(55.8)\end{array}$ & ++0.257 & $\begin{array}{l}92(48.4) \\
98(51.6)\end{array}$ & $\begin{array}{c}69(36.3) \\
121(63.7)\end{array}$ & ++0.022 \\
\hline $\begin{array}{r}\text { Table } \\
\text { Conjı }\end{array}$ & 1. Comparis & on of Age o & and Gen & nder in $\mathrm{Pa}$ & tients with & \\
\hline
\end{tabular}




\begin{tabular}{|c|c|c|c|c|}
\hline Microbial Culture & Diabetic & Non-diabetic & Total & p-value \\
\hline Positive & $69(36.3)$ & $42(22.1)$ & $111(29.2)$ & \multirow{3}{*}{ †+ 0.032} \\
\hline Negative & $121(63.7)$ & $148(77.9)$ & $269(70.8)$ & \\
\hline Total & $190(100)$ & $190(100)$ & $380(100)$ & \\
\hline \multicolumn{5}{|c|}{$\begin{array}{c}\text { Table 2. Result of Microbial Culture in Diabetic and } \\
\text { Non-diabetic Patients with Cataract }\end{array}$} \\
\hline No (\%), ††: Fisher's E & ct Test was & & & \\
\hline
\end{tabular}

\begin{tabular}{|c|c|c|c|}
\hline Isolated Microorganism & $\begin{array}{l}\text { Diabetic } \\
(\mathrm{N}=190)\end{array}$ & $\begin{array}{c}\text { Non-Diabetic } \\
(\mathrm{N}=190)\end{array}$ & $\begin{array}{c}\text { ††p- } \\
\text { Value }\end{array}$ \\
\hline Klebsiella & $3(1.6)$ & $0(0)$ & 0.123 \\
\hline Staphylococcus coagulase-negative & $40(21.1)$ & $26(39.4)$ & 0.059 \\
\hline Staphylococcus epidermidis & $9(4.7)$ & $6(3.2)$ & 0.600 \\
\hline Enterobacter & $0(0)$ & $3(1.2)$ & 0.248 \\
\hline Staphylococcus coagulase-positive & $0(0)$ & $6(3.2)$ & 0.030 \\
\hline Fungi & $17(8.9)$ & $1(0.5)$ & $<0.000$ \\
\hline \multicolumn{4}{|c|}{$\begin{array}{c}\text { Table 3. Bacterial and Fungal Pattern Isolated from } \\
\text { Conjunctival Cul-De-Sac }\end{array}$} \\
\hline \multicolumn{4}{|c|}{ No (\%), ††: Fisher's Exact Test was used. } \\
\hline
\end{tabular}

\begin{tabular}{|c|c|c|}
\hline Fungi & Diabetic & Non-Diabetic \\
\hline Aspergillus fumigatus & $2(11.76 \%)$ & 0 \\
\hline Aspergillus niger & $2(11.76 \%)$ & 0 \\
\hline Aspergillus flavus & $2(11.76 \%)$ & 0 \\
\hline Candida albicans & $2(11.76 \%)$ & 0 \\
\hline Candida glabrata & $1(5.88 \%)$ & 0 \\
\hline Candida parapsilosis & $2(11.76)$ & 0 \\
\hline penicillium & $3(17.65 \%)$ & 0 \\
\hline Mucormycosis & $3(17.65 \%)$ & 0 \\
\hline Cryptococcus neoformans & 0 & $1(100 \%)$ \\
\hline \multicolumn{2}{|c|}{ Total Conjunctival Cul-De-Sac } \\
\hline Table 4. Frequency of Fungal Pattern Isolated from \\
\hline
\end{tabular}

\section{DISCUSSION}

In this study, we assessed the conjunctival bacterial flora in diabetic and non-diabetic patients who referred for cataract surgery. It was accepted diabetes can lead to a decrease in immune system activity and this condition increase the risk of infection. On the other hand, patients with diabetes are susceptible to infection. ${ }^{10}$ Recently, Ansari et al. planned a retrospective cohort study and assessed 938,440 patients without diabetes and 48,584 diabetic patients. Their result showed the diabetic patients had a significantly increased of conjunctivitis. ${ }^{11}$ Based on our result, there was not statistically difference in the prevalence of microorganisms, including Klebsiella, Staphylococcus coagulase negative, Staphylococcus epidermidis, and Enterobacter in the diabetic and non-diabetic patients. In this study, Staphylococcus coagulase negative was higher in the diabetic patients in comparison with Non-diabetic group. (14.5\% Vs. 10.6\%). Staphylococcus epidermidis was also higher in the diabetic group. ${ }^{12}$ Some studies have shown in many people, Staphylococcus epidermidis is the normal conjunctival flora. ${ }^{12,13}$

Many studies showed Staphylococcus coagulase negative is an important factor in endophthalmitis after ocular surgery.3,14,15 Similar to our finding, Karimsab et al showed positive cultures in diabetic patients were higher in comparison to non-diabetic patients and Staphylococcus coagulase negative had a higher incidence in diabetic patients. ${ }^{16}$ In another study Martins found Staphylococcus coagulase-negative was a common microorganism in diabetic patients with retinopathy. ${ }^{17}$ Moreover Walker and colleagues also found similar results in their study. ${ }^{18}$ Similar to the results of these studies, Johnson et al. found positive relation between the conjunctival flora in diabetic patients and higher rate of gram-positive cocci, Staphylococcus coagulase negative and Staphylococcus aureus. ${ }^{19}$ The conjunctival fungal pattern of our diabetic patients showed an increased frequency in comparison to the non-diabetics. This difference was statistically significant (Table 2). Klotz et al. was reported that fungi can isolate from Conjunctival cul-de-sac of 6-25 percent of the normal population. ${ }^{20}$ Similar to our findings, Andrade reported that positive fungi isolated from Conjunctival cul-de-sac of diabetic patients. ${ }^{21}$ We find a significant difference in Staphylococcus coagulase-positive rate among the diabetic and non-diabetic patients. Based on our result frequency of Staphylococcus coagulase-positive in Non-diabetic patients was higher than diabetic patients. Our result was in contrast of reports in many studies. Karimsab and Suto et.al in two separated reports were shown in diabetic patients' rate of Staphylococcus coagulase-positive were higher in comparison of non-diabetic patients. ${ }^{16,22}$ Similar to our result Adam reported in 2015 Staphylococcus coagulase-positive was identified in $53 \%$ of non-diabetic patients and 30 percent in diabetic patients. This difference was statistically significant. They concluded Staphylococcus coagulase-positive the most common bacterial flora in nondiabetic patients. ${ }^{23}$ We did not find any relation between age and positive bacterial culture. In contrast of our study, some studies concluded that the elderly people were at high risk of positive conjunctival bacterial culture before cataract surgeries. Moreover, De Kaspar et al. showed patients with diabetes mellitus had a higher chance to have a positive conjunctival bacterial culture before ophthalmic surgeries. ${ }^{24}$

\section{Limitations}

The limitations of this study were the lack of examination of the functions of other organs of the body, including the kidneys, and the evaluation of serum creatinine levels. Also, in this study, occupation, place of residence and history of infectious diseases, the duration of diabetes diagnosis and treatment, and the way diabetes was treated was not investigated.

\section{CONCLUSIONS}

The results of this study showed that the rate of isolated Gram-negative bacteria, Klebsiella and Staphylococcus epidermidis were higher in the conjunctival flora in diabetic patients. Since these microorganisms possibly will be a main factor in conjunctival infections, treatment is necessary before cataract surgery to prevent postoperative endophthalmitis especially in diabetic patients who are relatively susceptible to infections.

\section{ACKNOWLEDGEMENT}

The authors thank all staff of ophthalmology department, Rafsanjan University of medical sciences, for their skilful technical assistance during the course of this study. 


\section{REFERENCES}

[1] Wilson M. Microbial inhabitants of humans: their ecology and role in health and disease. Cambridge University Press 2005.

[2] Callegan MC, Engelbert M, Parke DW 2nd, et al. Bacterial endophthalmitis: epidemiology, therapeutics and bacterium-host interactions. Clinical Microbiology Reviews 2002;15(1):111-24.

[3] Jabbarvand $M$, Hashemian $H$, Khodaparast $M$, et al. Endophthalmitis occurring after cataract surgery: outcomes of more than 480000 cataract surgeries, epidemiologic features and risk factors. Ophthalmology 2016;123(2):295-301.

[4] Sayin N, Kara N, Pekel G. Ocular complications of diabetes mellitus. World Journal of Diabetes 2015;6(1):92-108.

[5] Parvaresh MM, Mehrpouya AA, Anari RG, et al. Endophthalmitis caused by Acinetobacter spp. as the presenting manifestation of diabetes mellitus. Journal of Current Ophthalmology 2016;28(3):152-4.

[6] Javadi MA, Zarei-Ghanavati S. Cataracts in diabetic patients: a review article. J Ophthalmic Vis Res 2008;3(1):52-65.

[7] Fernandez-Rubio ME, Rebolledo-Lara L, Martinez-Garcia $\mathrm{M}$, et al. The conjunctival bacterial pattern of diabetics undergoing cataract surgery. Eye (London, England) 2010;24(5):825-34.

[8] Kawata T, Matsuo T. Positive bacterial culture in conjunctival sac before cataract surgery with night stay is related to diabetes mellitus. BMC Ophthalmol 2017;17(1):14.

[9] Moreno NP, Moreno RD, Sousa LB. Aerobic bacterial microbiota of the conjunctiva in diabetic patients with normal and altered glycated hemoglobin levels in two regions in Brazil. Arquivos Brasileiros de Oftalmologia 2014;77(6):351-4.

[10] Pearson-Stuttard J, Blundell S, Harris T, et al. Diabetes and infection: assessing the association with glycaemic control in population-based studies. The Lancet Diabetes \& Endocrinology 2016;4(2):148-58.

[11] Ansari AS, de Lusignan S, Hinton W, et al. The association between diabetes, level of glycaemic control and eye infection: Cohort database study. Primary Care Diabetes 2017;11(5):421-9.

[12] Mah FS, Davidson R, Holland EJ, et al. Current knowledge about and recommendations for ocular methicillin- resistant Staphylococcus aureus. Journal of Cataract \& Refractive Surgery 2014;40(11):1894-908.

[13] Sahin A, Yildirim N, Gultekin S, et al. Changes in the conjunctival bacterial flora of patients hospitalized in an intensive care unit. Arquivos Brasileiros de Oftalmologia 2017;80(1):21-4.

[14] Friling E, Montan P. Bacteriology and cefuroxime resistance in endophthalmitis following cataract surgery before and after the introduction of prophylactic intracameral cefuroxime: a retrospective single-centre study. Journal of Hospital Infection 2019;101(1):88-92.

[15] Gower EW, Keay LJ, Stare DE, et al. Characteristics of endophthalmitis after cataract surgery in the United States Medicare population. Ophthalmology 2015;122(8):1625-32.

[16] Karimsab D, Razak SK. Study of aerobic bacterial conjunctival flora in patients with diabetes mellitus. Journal of the Nepal Ophthalmic Society 2013;5(1):2832.

[17] Martins EN, Alvarenga LS, Hofling-Lima AL, et al. Aerobic bacterial conjunctival flora in diabetic patients. Cornea 2004;23(2):136-42.

[18] Walker CB, Claoue CM. Incidence of conjunctival colonization by bacteria capable of causing postoperative endophthalmitis. Journal of the Royal Society of Medicine 1986;79(9):520-1.

[19] Johnson MW, Doft BH, Kelsey SF, et al. The Endophthalmitis Vitrectomy Study. Relationship between clinical presentation and microbiologic spectrum. Ophthalmology 1997;104(2):261-72.

[20] Klotz SA, Penn CC, Negvesky GJ, et al. Fungal and parasitic infections of the eye. Clinical Microbiology Reviews 2000;13(4):662-85.

[21] Andrade AJ, Höfling-Lima AL, Yu MC, et al. Study of mycobiota in the healthy conjunctiva of diabetics who reside in the urban area of the city of São Paulo, Brazil. Arquivos Brasileiros de Oftalmologia 2006;69(1):75-83.

[22] Suto C, Morinaga M, Yagi T, et al. Conjunctival sac bacterial flora isolated prior to cataract surgery. Infection and Drug Resistance 2012;5:37-41.

[23] Adam M, Balcı M, Bayhan HA, et al. Conjunctival flora in diabetic and non-diabetic individuals. Turkish Journal of Ophthalmology 2015;45(5):193-6.

[24] De Kaspar HM, Ta CN, Froehlich SJ, et al. Prospective study of risk factors for conjunctival bacterial contamination in patients undergoing intraocular surgery. European Journal of Ophthalmology 2009;19(5):717-22. 